\title{
REFLEXÕES ACERCA DO IMPACTO SOCIAL E AMBIENTAL GERADO PELO AVANÇO DO AGRONEGÓCIO SUCROALCOOLEIRO
}

\author{
Munir Jorge Felicio ${ }^{1}$
}

\section{Caroline Kraus Luvizotto ${ }^{2}$}

Yeda Ruiz Maria ${ }^{3}$

RESUMO: O debate sobre agrocombustíveis e a soberania alimentar são componentes das novas configurações e dos novos protagonistas da realidade agrária e agrícola no Brasil e no mundo. Esse artigo tem como objetivo analisar os impactos sociais e ambientais gerados pelo avanço do capital sucroalcooleiro, que compreende o debate atual sobre a complexidade da questão agrária, pensada a partir das discussões em que se defrontam os diversos estudos desenvolvidos por teorias que contém distintas visões de mundo e de ser humano. É cada vez mais premente o debate sobre o equilíbrio entre a evolução econômica, a preservação ambiental e a equidade social, partindo do principio segundo o qual compreendese desenvolvimento rural como um conjunto de ações e práticas públicas e privadas dirigidas para atender as necessidades dos produtores e famílias rurais de menores recursos para melhorar sua qualidade de vida.

Palavras-chave: políticas públicas, agronegócio sucroalcooleiro, desenvolvimento territorial.

\footnotetext{
1 Doutor em Geografia; Docente do Mestrado em Meio Ambiente e Desenvolvimento Regional da Unoeste.munir@unoeste.br

2 Doutora em Ciências Sociais; Docente do Mestrado em Meio Ambiente e Desenvolvimento Regional da Unoeste.carol.luvizotto@hotmail.com.

3 Arquiteta Urbanista; Especialista em Gestão Ambiental; Mestranda em Meio Ambiente e Desenvolvimento Regional na Unoeste. yeda_rm@hotmail.com
} 


\section{INTRODUÇÃO}

A partir da década de oitenta, o termo sustentabilidade começa aparecer com muita frequência nos discursos políticos, em livros e artigos, na mídia, nos meios acadêmicos, nas instituições governamentais e não-governamentais, tornando-se um tema importante no debate social. A noção de sustentabilidade não é única, ou seja, há uma grande variedade de significados, multiplicidade de concepções, às vezes até controvérsias, estando muito longe da unidade ou do consenso, mostrando que é um conceito em disputa (ALMEIDA, 1997; MARZALL, 1999).

Vale considerar que as discussões sobre sustentabilidade surgem do reconhecimento da "insustentabilidade" do padrão de desenvolvimento das sociedades contemporâneas, pois tal padrão levou ao desencadeamento de crises econômicas, sociais, políticas, culturais e ambientais.

O debate sobre agrocombustíveis e a soberania alimentar são componentes das novas configurações e dos novos protagonistas da realidade agrária e agrícola no Brasil e no mundo. Ambas confirmam o modelo econômico de concentração das terras e centralização de renda e riqueza no campo e na cidade.

Nos estudos de Leff (2001) fica claro a concordância da associação dos problemas ambientais e a relação capitalista industrial, pautada nas relações entre o ser humano e a natureza como relações destrutivas, haja vista que o ser humano modifica seu habitat em prol do desejo de acomodação. A relação ser humano e natureza se estabelecem por meio do trabalho, um trabalho que domina e transforma para atender as necessidades individuais e coletivas (ARENDT, 1996).

Ademais, é indiscutível que para a produção acontecer o trabalho humano é indispensável, mesmo em situações de necessária dispensa de mão de obra. O processo produtivo normalmente envolve alguma externalidade negativa, por mais que se adotem tecnologias limpas de produção.

Esse artigo tem como objetivo analisar os impactos sociais e ambientais gerados pelo avanço do capital sucroalcooleiro, que compreende o debate atual sobre a complexidade da questão agrária, pensada a partir das discussões em que se defrontam os diversos estudos desenvolvidos por teorias que contém distintas visões de mundo e de 


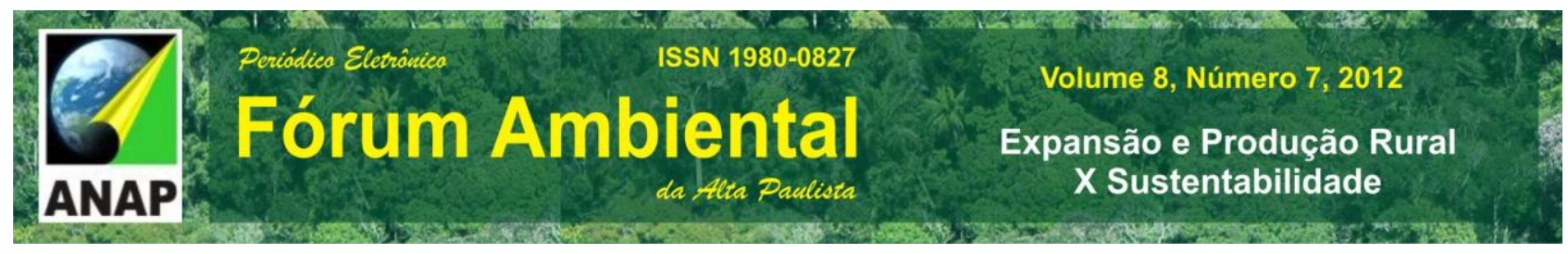

ser humano. Na primeira parte há um resgate histórico com a finalidade de proporcionar uma visão do desenvolvimento da agricultura no Brasil impulsionada por políticas públicas na implantação da nova base técnica para modernizar o complexo rural. Na segunda analisa o crescimento socialmente perverso do sistema capitalista agravado atualmente com a territorialização dos agrocombustíveis. E, na terceira, a necessária análise dos importantes impactos sociais e ambientais gerados pelo avanço do capital sucroalcooleiro denominado de agronegócio.

Durante toda a reflexão aqui apresentada, buscamos a implementação do conceito de sustentabilidade, com base na premissa de que é necessário atuar de maneira sistêmica, interdisciplinar e participativa e refletir de maneira profunda sobre a relação entre o ambiente natural, a sociedade e a economia.

\section{BREVE ANÁLISE DAS POLÍtICAS PÚBLICAS E O DESENVOLVIMENTO DA AGRICULTURA NO BRASIL}

Para compreender as questões - agrária e agrícola em que estão presentes decisões políticas e repercussões sociais torna-se imprescindível analisá-las em seu contexto histórico social como desenvolveram as análises de Hespanhol (1997); Silva (1996); Carvalho Filho (2001) e Sabourin (2007), entre outros, por contemplarem o necessário resgate histórico das últimas quatro décadas ampliando e problematizando os principais impactos impulsionados pela expansão do capital na agricultura no Brasil.

Ao analisar as políticas públicas que fizeram frente à crise da agricultura brasileira Hespanhol (1997) propõe um quadro geral visando compreender o desenvolvimento do campo no Brasil no período de 1960 a 1980. Explica que, enquanto os pequenos produtores não conseguiram alterar sua base técnica produtiva sofrendo a exclusão do meio rural em virtude do caráter excludente e concentrador do processo modernizante, a oligarquia rural, os latifundiários usufruíram dos subsídios governamentais ampliando seu peso político e fortalecendo suas organizações. Os governos militares selaram um verdadeiro pacto com a classe dominante (burguesia urbana-industrial e aristocracia rural) em favor da chamada modernização da agricultura brasileira que se inicia na década de 1950, todavia torna-se expressiva a partir de meados dos anos 1960.

VIII Fórum Ambiental da Alta Paulista, v. 8, n. 7, 2012, p. 12-28. 


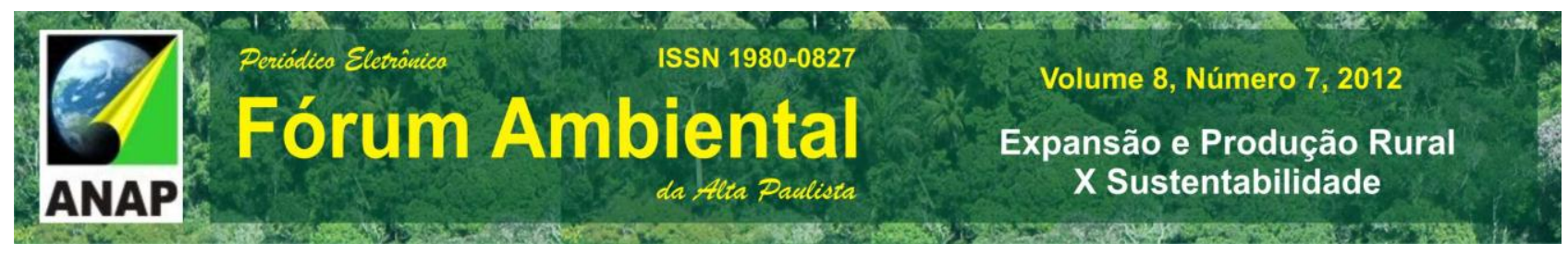

Até meados dos anos 1960 a agricultura brasileira era rotulada de feudal em virtude da elevada concentração fundiária, da reduzida produção, dos baixos níveis de produtividade e da pequena articulação do setor ao mercado. Entre 1965 e início dos anos 1980, no entender de Hespanhol (1997), o crédito rural subsidiado denominado Sistema Nacional de Crédito Rural - SNCR - constituiu-se no principal instrumento de política agrícola. Através da oferta de crédito rural farto e barato, o governo procurou compensar o setor agrícola da transferência de recursos a que estava submetido. Tal medida visava expandir o mercado interno de máquinas e insumos industriais e ampliar a oferta de produtos exportáveis e de matéria prima para a indústria. De sorte que o processo de modernização da agricultura brasileira foi fortemente subvencionado pelo Estado.

Outro autor que contribui para a compreensão das questões - agrária e agrícola é Silva (1996) para quem o Estado ao promover a industrialização da agricultura beneficiou grandes proprietários de terras e grandes industriais promovendo profunda exclusão social. A partir dos anos 1970 os complexos agroindustriais -CAls - substituem os complexos rurais pela criação do SNCR nos e dos governos militares.

Essa integração de capitais levou também à verdadeira territorialização da burguesia, na medida em que o mercado de terras tornou-se um ativo alternativo para as aplicações de capitais. O resultado foi que os grandes capitalistas passaram a ter uma face agrária, não oposta, mas articulada às faces industrial $e$ financeira (SILVA, 1996, p.44).

Os complexos agroindustriais consistem na somatória dos recursos da agricultura com os esforços de políticas públicas ao reunir numa só unidade empresarial a produção de matéria prima e indústria processadora. Assim, as indústrias produziram máquinas e insumos químicos modernizando a agricultura e as agroindústrias processadoras se desenvolveram pelos fortes incentivos de políticas governamentais específicas como fundos de financiamento para determinadas atividades, programas de apoio a certos produtos agrícolas, crédito para aquisição de máquinas, equipamentos e insumos modernos.

Prosseguindo neste breve resgate histórico o Brasil, no início dos anos 1990 segundo Carvalho Filho (2001), é colocado na trilha da chamada "integração competitiva", da modernização da agricultura, da constituição e fortalecimento do agronegócio, da 


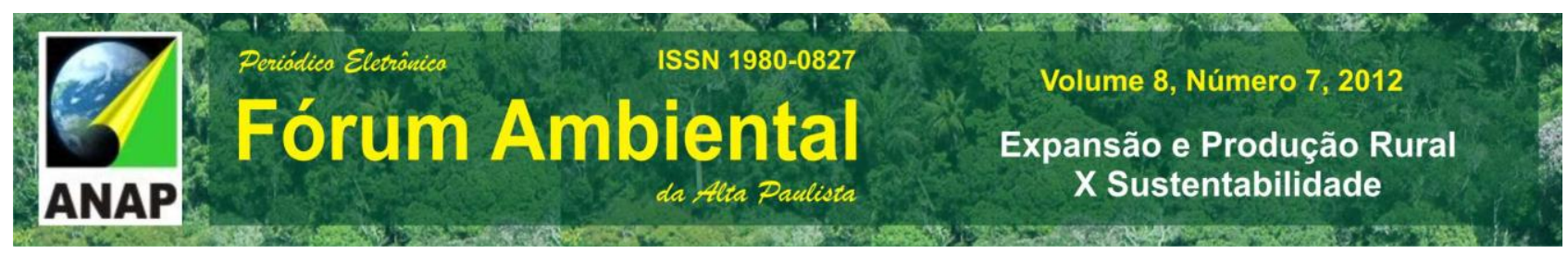

busca pela competitividade internacional, da "modernização" (redução/destruição) do aparelho de Estado, com implementação de instrumentos de política agrícola via mercado. Nesta lógica o agronegócio substituirá os complexos agroindustriais. Contudo,

é preciso entender que o desenvolvimento rural não pode ser tratado isoladamente. Não se pode aceitar que o desenvolvimento rural signifique apenas modernização tecnológica e crescimento da produção. Desenvolvimento inclui distribuição e redução das desigualdades entre pessoas e entre regiões (CARVALHO FILHO, 2001, p. 196).

As políticas públicas durante os anos 1990 no decorrer dos dois mandatos de FHC não alterou a estrutura fundiária que permanecia entre as mais concentradas do planeta. Os conflitos agrários existentes são consequências dessa situação. Em 1998 já no segundo mandato, o governo FHC implanta novo modelo de desenvolvimento rural e anunciou a mudança no sistema de obtenção de terras para fins de reforma agrária cujo instrumento principal passa a ser o Banco da Terra e leilões de terra em detrimento das desapropriações. A fórmula é simples: um grupo de agricultores sem terra identifica a área que deseja, faz um processo sumário para aquisição da gleba e apresenta-o à unidade técnica do estado. Se aprovado, o grupo receberá o financiamento para a compra da terra, com prazo de pagamento de 20 anos. Para isso, o INCRA fará convênios com o Banco do Brasil e bancos regionais, como o do Nordeste, que vai operar o programa no primeiro momento.

A dualidade da política agrícola brasileira introduzida no segundo governo FHC foi mantida, institucionalizada e até exacerbada do governo Lula. A agricultura familiar com 42 milhões de estabelecimentos e $70 \%$ das propriedades ativas agrícolas é administrada pelo Ministério do Desenvolvimento Agrário - MDA - e a agricultura empresarial com 550 mil estabelecimento com apenas $12 \%$ do total dos estabelecimentos é administrada pelo Ministério da Agricultura, Pecuária e Abastecimento (MAPA) ${ }^{4}$. Os créditos financeiros para a agricultura familiar são, no máximo, $20 \%$ daqueles destinados à agricultura empresarial.

No primeiro e segundo governo Lula três programas são encarregados de promover o desenvolvimento da agricultura familiar, segundo Sabourin (2007). Trata-se

\footnotetext{
$4 \quad$ A iniciativa em dividir entre ministérios o atendimento da agricultura ocorreu no segundo governo FHC como resposta à chacina de Eldorado dos Carajás em 1997.
} 


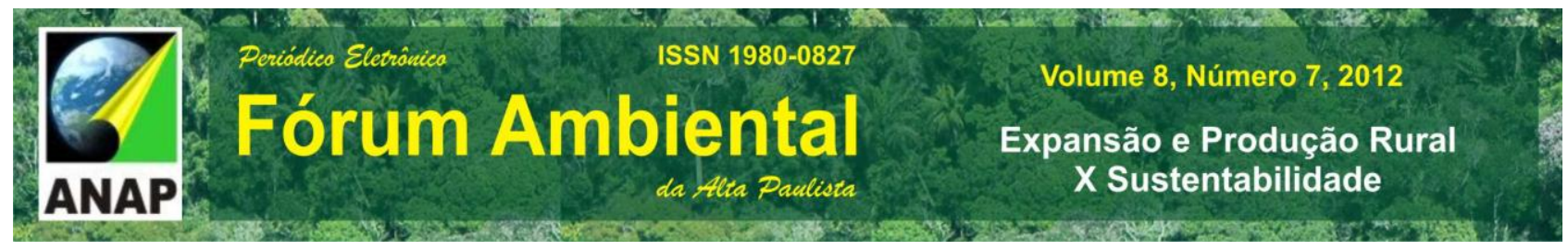

do Programa Nacional de Fortalecimento da Agricultura Familiar - Pronaf - entregue à Secretaria da Agricultura Familiar; do Programa de Desenvolvimento Sustentável dos Territórios Rurais - PDSTR - também denominado de Territórios da Cidadania entregue à Secretaria de Desenvolvimento Territorial e do Programa Nacional de Reforma Agrária entregue à Secretaria da Reforma Agrária. Conforme Sabourin (2007, p. 7):

As três secretarias do MDA confiadas ao Partido dos Trabalhadores foram repartidas entre responsáveis e equipes vindos dos movimentos e organizações sindicais e profissionais, concorrentes entre elas ou ligadas a correntes diferentes do PT: a SRA à Contag, a SAF à Federação dos Trabalhadores da Agricultura Familiar (Fetraf), o Incra ao Movimento dos Trabalhadores Sem Terra (MST) e a SDT às cooperativas da agricultura familiar.

O Pontal do Paranapanema (SP) é um dos sessenta territórios atendidos desde a primeira etapa do programa. Os investimentos visam ações de apoio a atividades produtivas, cidadania e acesso a direitos e recuperação e qualificação de infra-estrutura (vide informações em www.territoriosdacidadania.gov.br). São ações com as quais o governo federal pretende reduzir desigualdades regionais, levar direitos e promover o desenvolvimento territorial.

Todavia, o que tem marcado historicamente esse território é o processo de disputa entre a expansão do capital e a resistência camponesa como demonstrou Leite (1998). A conflitualidade (FERNANDES, 2008) como processo de enfrentamento perene alimentado pela contradição estrutural do capitalismo produz, necessariamente, a concentração de riqueza de um lado e, expande a miséria do outro.

A viabilidade para a racionalidade da preservação ambiental virá à medida que se assegure também a garantia de reprodução dos grupos sociais envolvidos, a sustentabilidade.

Assim sendo David et. al. (1997) afirma que a demanda por terra e a sua ocupação efetiva exigem uma política agrária mais criativa e efetiva, que dê condições de manutenção na atividade agrícola para a população rural existente e permita uma partilha justa da terra de maneira sustentável. Ou seja um programa de reforma agrária que busque transformar as condições de vida de seus beneficiários deve estar inserido em uma estratégia produtiva que assegure a sustentabilidade desta agricultura, que deve ser pensada não somente como meio de sobrevivência das famílias, mas principalmente 


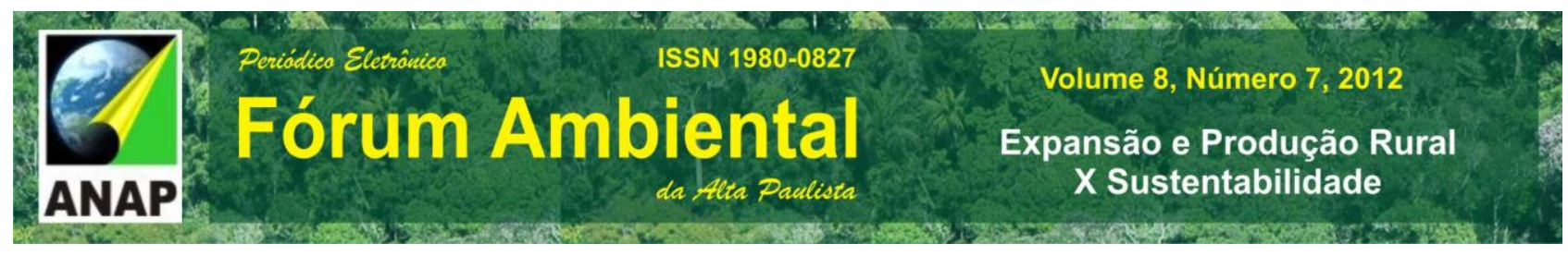

como fonte geradora de excedentes que assegurem novos investimentos e permitam a ampliação da produção e produtividade da agricultura brasileira.

Na última década, devido ao processo de mudança de matriz energética, aumentou a intensidade da expansão das áreas de culturas para a produção dos agrocombustíveis, exigindo releitura dos modelos teóricos e de desenvolvimento territorial. A região do Pontal do Paranapanema é uma das áreas de expansão do agronegócio sucroalcooleiro do Estado de São Paulo e, por essa razão, os conflitos agrários tendem a se intensificar, aprofundando as críticas à territorialização dos agrocombustíveis.

Qualquer que seja o nível de desenvolvimento de uma sociedade, as interações entre o homem e o meio ambiente são permanentes, intensas e íntimas.

\section{A TERRITORIALIZAÇÃO DOS AGROCOMBUSTÍVEIS}

O crescimento socialmente perverso do sistema capitalista em franca expansão na Região do Pontal do Paranapanema serve como base empírica para a verificação e aprofundamento do debate referente ao esgotamento das distintas dimensões como a econômica, política e a ambiental do modelo de desenvolvimento da agricultura brasileira. Diariamente as principais corporações globais da comunicação difundem a magnitude dos problemas em curso advindos do aquecimento global, a finitude dos combustíveis fósseis (em particular do petróleo) e seus efeitos para o agravamento dos problemas climáticos em face da sua utilização massiva em todo o planeta.

Analisar o território significa apreender as relações sociais que o determinam, o que na atualidade significa fazer uma analise que abarque o modo capitalista de produção e suas implicações, numa perspectiva de entendimento de que as relações sociais no mundo atual são por ele determinadas. (BOMBARDI, 2004, p. 47).

Tem-se aqui que a produção de agroenergéticos, como no caso da cana-deaçúcar, é determinada pelo capital; este detém o controle tanto do território, quanto da produção e do processo industrial, ou seja, este é quem monopoliza o território. Este processo acaba por gerar contradições que se manifestam inclusive territorialmente, 


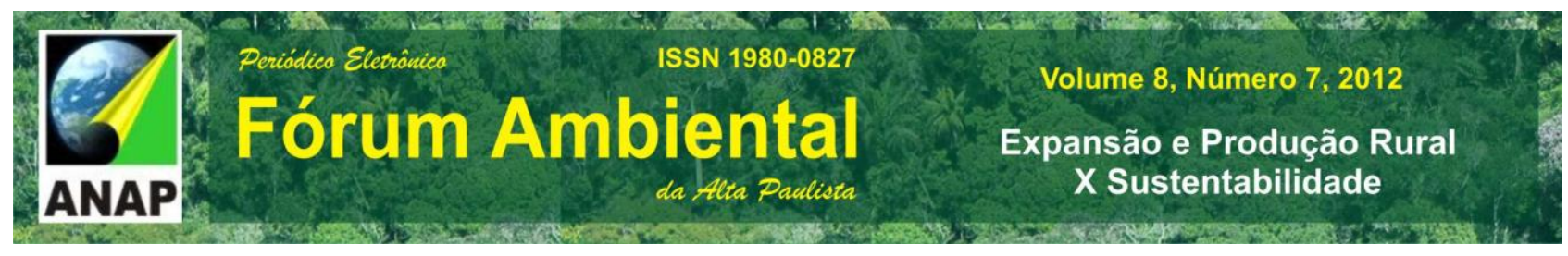

assim como no caso das tensões geradas no campo, cujo resultado tem sido a retirada do camponês do seu local de trabalho e a eclosão de diversos conflitos por terra.

Esse cenário que se desenvolve na segunda década de século XXI tem chamado a atenção o debate internacional referente a premência da criação e difusão de fontes energéticas alternativas. A consequente implantação de políticas públicas de desenvolvimento do campo relacionadas com os agrocombustíveis uma vez que o mundo está às vésperas de uma transição para uma nova matriz energética que visa o solo e não o subsolo como fonte mãe de combustíveis renováveis e sustentáveis. Concomitantemente, verifica-se o agravamento da tenebrosa problemática da fome e da miséria de crescentes efetivos da população mundial.

A agricultura capitalista, por sua vez, apropria-se das políticas públicas de incentivo à produção de agrocombustíveis territorializando o agronegócio sucroalcooleiro mediante a incorporação de mais terras, modernização de usinas pré-existentes e multiplicação do número destas, especialmente nos estados de São Paulo, Minas Gerais, Mato Grosso do Sul e Goiás. Outra forma de expansão deste sistema agrícola é a multiplicação de grandes fornecedores de cana e a transformação de pastagens em áreas de produção agrícola, principalmente com a produção de grãos e/ou cana de açúcar, que muitas vezes tem promovido a reconversão produtiva e retirado áreas de pastagens de baixa produtividade.

Há ainda a criação de políticas públicas para integração subordinada de parcela do campesinato ao agronegócio, defendida inclusive por parte dos movimentos sociais e entidades ligadas às lutas no campo, mediante esta nova vaga das culturas energéticas destinadas à produção de etanol e/ou como é o caso do Programa Nacional de Produção e Uso do Biodiesel (PNPB), criado em 2005.

Nas análises acadêmicas e políticas, como também, no entendimento de parte dos movimentos sociais é de que a matriz energética assentada nos combustíveis fósseis, que está em fase de esgotamento, não implica apenas numa transição energética, mas numa transição estrutural que perpassa a valorização econômica do campo porque este espaço vai se constituir no principal fornecedor de matéria-prima para a produção de energia. 


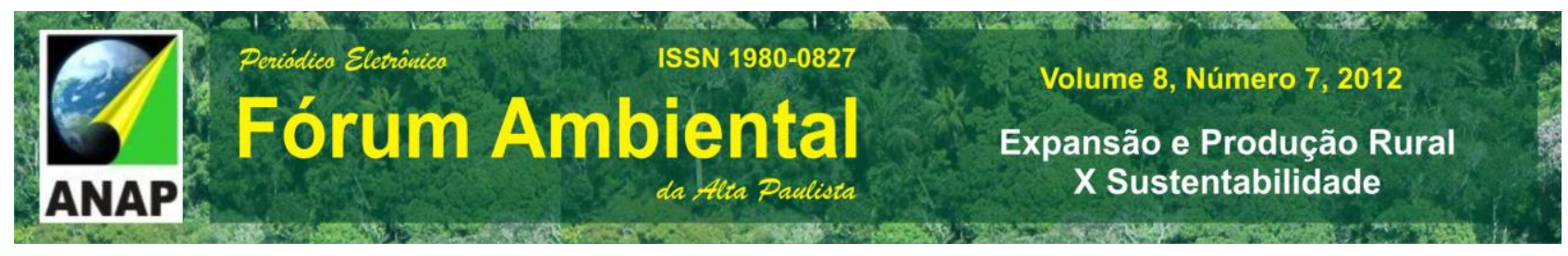

Assim, seria a vez do campo, e os camponeses devem saber inserir-se em cadeias produtivas de agrocombustíveis (como se elas não fossem monopolizadas por corporações nacionais e transnacionais), para tirar vantagens na produção de agrocombustível, principalmente biodiesel e garantir sua existência. Os camponeses, organizados em cooperativas dedicadas a produção de agrocombustíveis deveria combinar a produção de energia (soberania energética) com produção de alimentos (soberania alimentar).

Uma possível dependência agroenergética de países produtores de combustíveis de biomassa como o Brasil tem feito muitos governos e empresas privadas de países centrais investirem em pesquisas científicas capazes de extrair combustível de outras fontes de biomassa. Este é o caso de recentes pesquisas de engenharia genética e biologia sintética para a produção do etanol celulósico, com a quebra da molécula da celulose, o que provoca a liberação da possível dependência de países produtores de cana de açúcar.

O Censo Agropecuário do IBGE (1995/1996) em análise do volume da produção brasileira em comparativo com lavouras temporárias e lavouras permanentes, revelam que a maioria da produção agrícola nacional advém das pequenas unidades de produção, inclusive se considerarmos as principais commodities como o milho, soja, café, laranja e cacau. Portanto, o agronegócio não é o responsável pela prosperidade agrícola nacional, como querem demonstrar algumas análises.

O que está em curso neste momento é uma espécie de "corrida pelo álcool", entenda-se por áreas cultiváveis e por linhas de crédito - visando o financiamento da instalação de novas usinas. Existe hoje no país mais de 280 usinas em fase de planejamento e montagem, no entanto, segundo o autor, "há estudos indicando que para - Brasil abastecer apenas cinco por cento do mercado mundial de etanol, seria necessário aumentar seis vezes a produção atual, ou seja, alcançar a produção de cem bilhões de litros, o que expandiria a cana para 36 milhões de hectares. E seria necessário o dobro para substituir $10 \%$ do consumo mundial de gasolina, ou seja, 72 milhões de hectares" (OLIVEIRA, 2007).

É nas pequenas unidades de produção e assentamentos de reforma agrária que têm surgido diferentes alternativas de produção e re-socialização como as de 
agroecologia, socioeconomia solidária, educação do campo, produção alimentar para o mercado nacional e de commodities. O debate sobre agrocombustíveis e soberania alimentar caiu rapidamente em polêmica, vinculando uma suposta crise na oferta de alimentos com demanda crescente do mercado de combustíveis para matérias-primas agrícolas.

\section{IMPACTO SOCIAL E AMBIENTAL GERADO PELO AVANÇO DO AGRONEGÓCIO SUCROALCOOLEIRO}

A história agrícola do Oeste do Estado de São Paulo e, especialmente do Pontal do Paranapanema, registra intensas mobilizações destinadas à implantação de ciclos produtivos como o café, algodão, amendoim e pastagens. A utilização desses solos para produção de alimentos e matérias primas, sem os devidos cuidados conservacionistas, resultou num processo contínuo de alteração da estrutura natural, ocasionada pelos implementos agrícolas e preparo intensivo, resultando no aumento das perdas por erosão (NUNES, 2006).

A região do Pontal do Paranapanema localizada a Oeste do Estado de São Paulo tem sofrido, ao longo das décadas, intenso processo de desmatamento, substituindo áreas nativas de Mata Atlântica e de cerrados, por pastagens e cultivos agrícolas. Este processo histórico é decorrente de uma série de políticas de âmbito público e privado, cujo objetivo era a ocupação do território do Pontal do Paranapanema. Um dos principais resultados desta ocupação, sem planejamento adequado, são os graves problemas de erosão em solos com predomínio de classes texturais arenosas, configurando-se em algumas áreas um quadro de formação de voçorocas, destruição de nascentes, assoreamento de inúmeros córregos, etc. Além deste quadro de degradação ambiental, nos últimos anos tem ocorrido também, um expressivo avanço da monocultura da cana-de-açúcar na região, em especial nos assentamentos rurais, cujos usineiros arrendam terras destinadas à reforma agrária com a conivência do Instituto de Terras do Estado de São Paulo (ITESP).

O avanço do agronegócio sucroalcooleiro reforça as características do modelo agroexportador dependente monocultural e latifundiário da agricultura desenvolvida historicamente no Brasil como são demonstradas nas análises de Silva 


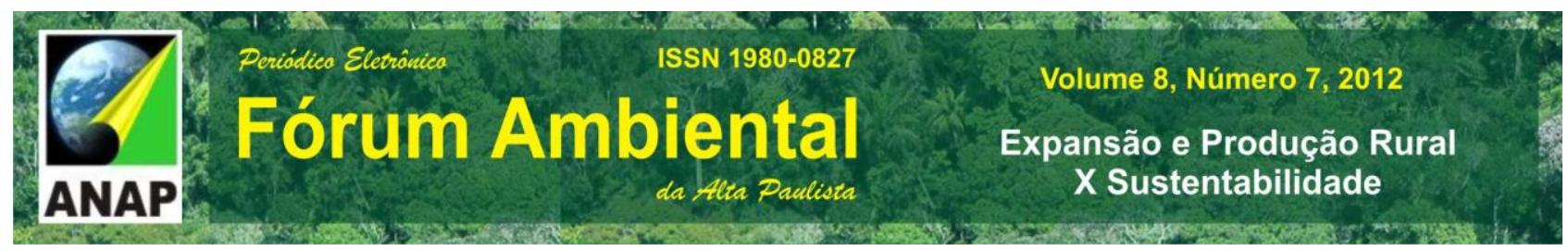

(1996), Oliveira (1991), Welch e Fernandes (2008) e Felício (2011) entre outras. Procuram compreender de que forma a industrialização da agricultura promoveu a transformação do complexo rural para uma dinâmica dirigida pelos complexos agroindustriais e desses para o agronegócio. O agronegócio consiste num complexo de sistemas - agricultura, indústria, mercado e finanças - com poder para comandar e controlar o desenvolvimento da agricultura visando novos modelos produtivos pelos processos de comoditização, quimiquização, as novas formas de organização do trabalho e inovações técnicocientíficas.

Meszáros (2002) salienta que o objetivo dessas mudanças, além de buscar conter as contradições sociais inerentes à "crise estrutural do capital", que se manifestou no interior do sistema desde meados dos anos 1970, visa garantir também novas bases de produção e reprodução econômica e novas formas de controle sobre o trabalho e sobre a natureza para repor o movimento incessante de expansão e acumulação do capital.

Ademais é preocupante o fato de que essas transformações, além de gerar mais um modelo de acumulação capitalista, também se instaura sobre a natureza um novo processo de controle e domínio, ou seja, novas formas de extração dos recursos naturais e minerais necessários para reprodução do capital se impõem. Assim sendo salta das entrelinhas a compreensão de que a exploração intensiva e destrutiva da natureza advindas das necessidades do capital causa problemas na estruturação social e econômica.

O Brasil é o maior produtor de cana-de-açúcar do mundo, seguido por Índia, Tailândia e Austrália. A área plantada até o ano de 2008 atingiu mais de 8 milhões de hectares, representando um aumento de 1 milhão e 124 mil hectares quando comparado com a safra anterior (IBGE/PAM, 2010). No intervalo entre 2001 e 2008, houve um acréscimo de $63 \%$ na área plantada, sendo que, nesse último ano, a ocupação alcançou $14 \%$ de todas as terras dedicadas à lavoura temporária no país (IBGE/PAM, 2010).

Essa expansão do comércio sucroalcooleiro em especial na região CentroSul do Brasil acontece em decorrência de algumas estratégias referentes ao setor: a) o crescente aumento do comércio de açúcar e álcool no mercado interno e externo; b) crise e elevação do preço do barril de petróleo no mercado internacional, bem como sua 
escassez e alto nível de poluição (emissão de CO2 na atmosfera); c) aumento da demanda interna por álcool hidratado, devido ao aparecimento dos novos modelos de carros bicombustível; d) devido às alterações climáticas e ao aquecimento global provocado pela intensa emissão de $\mathrm{CO} 2$, o protocolo de Kyoto ${ }^{5}$ defende a redução da emissão de gás carbônico, o que tem contribuído para gerar uma demanda internacional por álcool anidro de outros países da Europa, Ásia e América.

Aparentemente tem-se um desenvolvimento limpo e sustentável. No entanto camufla-se as mazelas sociais e ambientais que degradam não apenas a vida de milhares de trabalhadores (migrantes) canavieiros e comunidades rurais, mas também o meio ambiente e diversos ecossistemas, que correm o risco de desaparecerem devido à expansão dos canaviais.

A instalação das usinas de açúcar e álcool na região do Pontal do Paranapanema, associado ao histórico de políticas públicas, por parte das esferas estaduais e federais, no qual pouco tem contribuído ao desenvolvimento social e ambiental dos assentamentos rurais, gerando baixos investimentos em infraestrutura básica e assistência técnica adequada à realidade ambiental das áreas, tem levado os assentados rurais a arrendarem suas terras para os usineiros, através das "parcerias", a fim de obterem maior renda. Dessa forma, a expansão do cultivo da cana-de-açúcar na região do Pontal do Paranapanema, em especial nos assentamentos rurais, evidencia uma disputa sócio-territorial e ambiental, de um lado, para produzir a cana e, de outro, para a produção de alimentos por parte dos assentamentos rurais.

Neste contexto Dupas (2008) ressalva que apesar de seus altos níveis de produtividade, a agricultura contemporânea.

(...) caracteriza-se por baixa eficiência energética, grande erosão genética e das áreas de cultivo e contaminação do solo e da água, gerando riscos imprevisíveis para o ambiente e a saúde. A degradação ambiental é decorrente das técnicas de produção contemporâneas e da direção dos vetores tecnológicos que sustentam a atual lógica do capital (DUPAS, 2008, p. 8).

\footnotetext{
${ }^{5}$ O Protocolo de Kyoto é um instrumento internacional, ratificado em 15 de março de 1998, que visa reduzir as emissões de gases poluentes. Estes, são responsáveis pelo efeito estufa e o aquecimento global. Entrou oficialmente em vigor no dia 16 de fevereiro de 2005, após ter sido discutido e negociado em 1997, na cidade de Kyoto - Japão..
} 


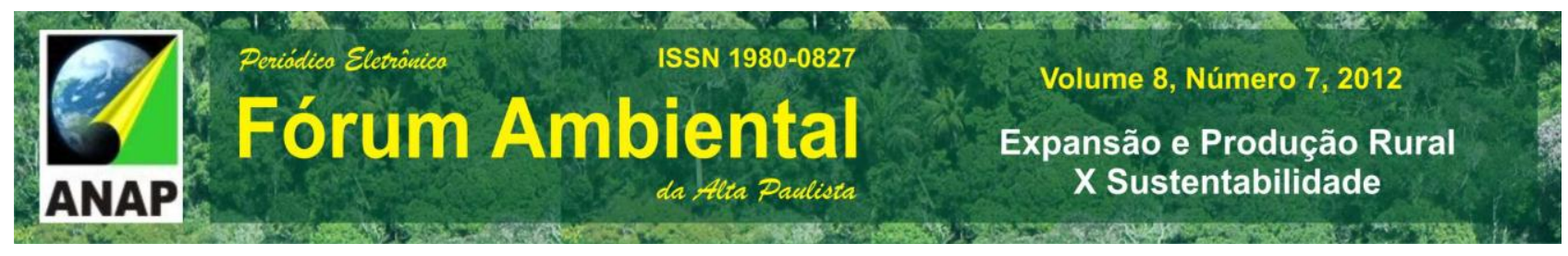

É preocupante na atual situação expansiva da cana-de-açúcar a intensificação dos problemas ambientais, como a periódica destruição e degradação de ecossistemas inteiros, por meio da prática habitual das queimadas.

(...) as queimadas provocam periodicamente a destruição e degradação de ecossistemas inteiros, tanto dentro como junto às lavouras canavieiras, além de dar origem a uma intensa poluição atmosférica, prejudicial à saúde, e que afeta não apenas as áreas rurais adjacentes, mas também os centros urbanos mais próximos (SZMRECSÁNYI, 1994, p.73).

Além da poluição provocada pela queima da cana antes do corte, a queima do bagaço para a geração de energia durante o processo de fabricação do açúcar e etanol gera o material particulado (MP), isto é, monóxido e dióxido de carbono e óxido nitrogênio, toxinas residuais de cinzas, fuligens e outros materiais que são inalados tanto pelos trabalhadores canavieiros durante o corte manual da cana, quanto pelos moradores das áreas urbanas, cercadas pelo "mar de cana". A respiração dessas toxinas, ao penetrarem nos pulmões gera uma diminuição da capacidade respiratória (SILVA, 2008).

No que se refere à fauna e à flora, as queimadas provocam a morte de várias espécies de animais, como cobras, tatus, lagartos, capivaras, lobos, seriemas, onças, dentre outros que habitam essas áreas ou que se encontra em extinção. As reservas e florestas também são afetadas, na medida em que até mesmo as matas ciliares são destruídas para o plantio de cana, havendo, portanto, o desrespeito às Áreas de Preservação Permanente (APP' s) (SILVA, 2008).

Vale ressaltar o processo contraditório de criação de emprego pela expansão da área plantada, onde a legislação ambiental em diversos estados, principalmente em São Paulo, incentiva a mecanização da colheita da cana-de-açúcar a fim de se eliminar o processo de colheita manual por meio de queimadas. Assim, verificase uma busca de trabalhadores mais qualificados para operar os equipamentos sofisticados e a destruição de postos de trabalho pela mecanização da colheita da cana, já que se supõe que cada colheitadeira de cana poderá substituir de 80 a 120 trabalhadores. Acredita-se que estes trabalhadores dificilmente conseguirão se adaptar em outro tipo de emprego, pois em sua maioria não possuem qualificação suficiente para entrar no mercado de trabalho cada vez mais avançado (PALETTA, 2004; RODRIGUES \& ORTIZ, 2006; CARVALHO, 2007). 


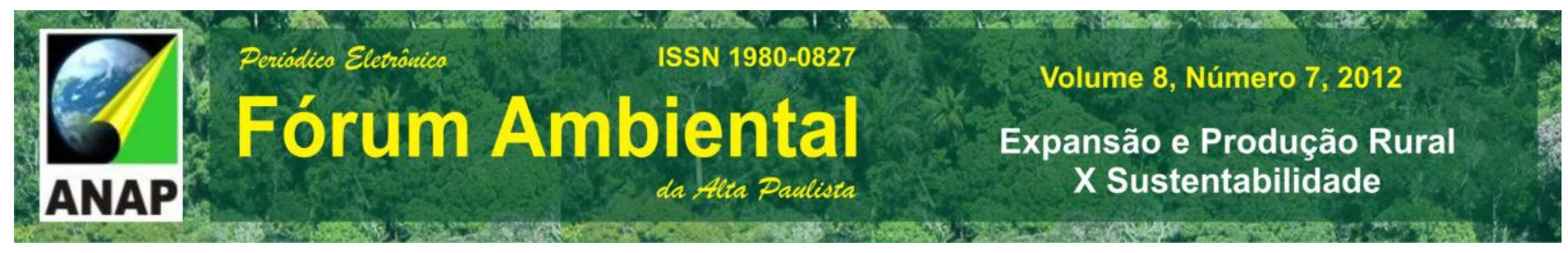

Ficam evidentes as contradições entre capital e natureza. Acentua-se ainda mais diante da ocorrida ampliação dos assentamentos no cultivo da cana-de-açúcar, com a quebra da unidade da família camponesa, agora estimulada a fazer parte de um grande negócio, alardeado como bem-sucedido, que, para a maioria dos entrantes, já expressa os principais aspectos negativos, tais como: endividamento, desagregação da família trabalhadora e frustração.

É indiscutível que o aumento na produção de açúcar, etanol e a co-geração de energia elétrica é contribuição positiva para o desenvolvimento da economia brasileira. Entretanto vale frisar a necessária atenção, pois dependendo das proporções atingidas e sem um posicionamento mais efetivo das autoridades governamentais em termos principalmente do desenvolvimento de políticas públicas de qualificação e de inserção da mão-de-obra em outros mercados de trabalho, evitando a aglomeração da mesma nos centros urbanos (êxodo rural), essa fonte de riqueza econômica é passível de se transformar em pesado problema socioambiental.

\section{CONSIDERAÇÕES FINAIS}

A modernização da agricultura brasileira que se inicia na década de 1950 visava desenvolver o mercado interno num processo histórico de mudanças do complexo rural em complexos agroindustriais com a participação cada vez maior do Estado implantando políticas públicas especificas dirigidas a cada complexo agroindustrial. Os elementos destacados dessa mudança significativa são: a) crescimento rápido da urbanização; b) crescimento do comércio exterior agrícola; c) mudança na base técnica de produção rural e d) consolidação simultânea de um sistema nacional de crédito rural.

O projeto de desenvolvimento da agricultura ficou conhecido por "modernização conservadora" por manter intocável a estrutura fundiária, envolveu de forma profunda o Estado (que foi seu financiador), mas rejeitou o enorme contingente primitivo de população rural, ao erigir a integração de capitais no complexo agroindustrial. Desta forma, os pequenos produtores se associam de forma subordinada ou são rejeitados do processo de crescimento econômico sob a égide do capital financeiro. É importante destacar a maneira intima e umbilical de como se dá a associação do grande 


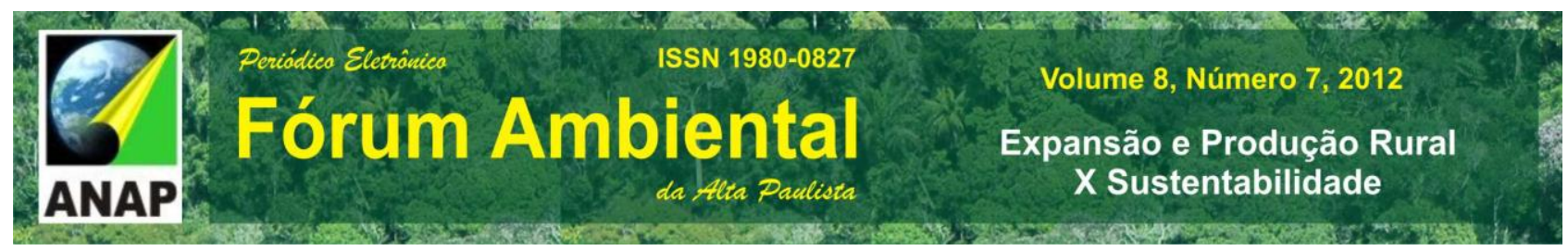

capital com o Estado que lhe propõe condições propícias para seu avanço na agricultura brasileira.

Caracteriza esse avanço do capital na agricultura o desenvolvimento de fontes energéticas alternativas tendo em vista o cenário na segunda década de século XXI com o debate internacional referente a conservação ambiental de um lado e a transição mundial para uma nova matriz energética, de outro. Por isso é cada vez mais premente o debate sobre o equilíbrio entre a evolução econômica, a preservação ambiental e a equidade social, partindo do principio segundo o qual compreende-se desenvolvimento rural como um conjunto de ações e práticas publicas e privadas dirigidas para atender as necessidades dos produtores e famílias rurais de menores recursos para melhorar sua qualidade de vida.

\section{REFERÊNCIAS BIBLIOGRÁFICAS}

ALMEIDA, Jalcione. "Da ideologia do progresso à idéia de desenvolvimento (rural) sustentável" In: ALMEIDA, Jalcione e NAVARRO, Zander (Orgs.), Reconstruindo a agricultura: idéias e ideais na busca do desenvolvimento rural sustentável, Porto Alegre, Editora da Universidade (UFRGS), 1997.

ARENDT, Hannah. A Condição Humana. Rio de Janeiro Forense, São Paulo, EDUSP, 1981.

BOMBARDI, Larissa Mies. O bairro reforma agrária e o processo de territorialização camponesa. São Paulo: Annablume, 2004.

CARVALHO FILHO, José Juliano de. Política agrária do governo FHC: desenvolvimento rural e a Nova Reforma Agrária. In: Políticas Públicas e Agricultura no Brasil. Porto Alegre: Ed. Unisinos, 2001.

CARVALHO, H. M. de. Impactos Econômicos, Sociais e Ambientais devido à Expansão da Oferta de Etanol no Brasil. Curitiba, Setembro, 2007. Disponível em: http://www.cptpe.org.br/files/impactos.pdf. Acesso: set. De 2012.

DAVID. M. B. A., WANIEZ P.; BRUSTLEIN, V. Atlas dos beneficiários da reforma agrária. Estudos Avançados, v. 11, n. 31, p.51-68, 1997.

HESPANHOL, Antonio Nivaldo., Políticas Públicas, modernização e crise da agricultura brasileira. In: Revista Faz Ciência, volume 1, №. 1, p. 38-49, Francisco Beltrão, 1997. 


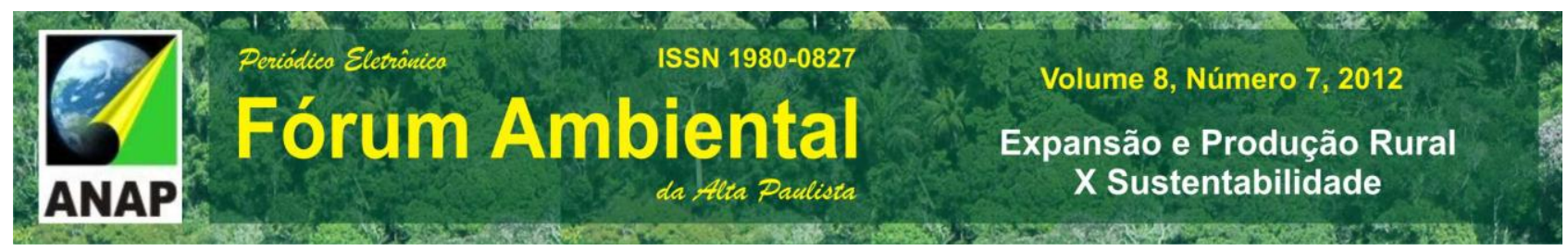

DUPAS, G (Org.). Meio ambiente e crescimento econômico - tensões estruturais. São Paulo: Editora UNESP, 2008.

FELICIO, Munir Jorge. Contribuição ao debate paradigmático da questão agrária e do capitalismo agrário. 2011. 214 folhas. Tese (Doutorado em Geografia), apresentada no Programa de Pós-Graduação em Geografia. Universidade Estadual Paulista, campus de Presidente Prudente.

FERNANDES, B.M.. Conflitualidade e Desenvolvimento Territorial. In: BUAINAIN, Antônio Marcio (org.) Luta pela Terra, Reforma Agrária e Gestão de Conflitos no Brasil. Editora Unicamp, 2008, p. 173-224.

IBGE/PAM - Instituto Brasileiro de Geografia e Estatística. Pesquisa Agrícola Municipal 2008. Acesso em: 12 de setembro de 2012.

LEFF, Enrique. Saber Ambiental: sustentabilidade, racionalidade, complexidade, poder. Tradução Lúcia Mathilde Endlich Orth. Petrópolis, Rio de Janeiro. Vozes, 2001

LEITE, J. F. A ocupação do Pontal do Paranapanema. São Paulo: Hucitec, 1998.

MANTEGA, Guido, A Economia Política Brasileira. 6ª edição, Petrópolis: Vozes, 1991.

MARZALL, K. Indicadores de sustentabilidade para agroecossistemas. 1999. 212 p. Dissertação (Mestrado em Fitotecnia) - Faculdade de Agronomia, Programa de PósGraduação em Fitotecnia, UFRGS, Porto Alegre.

MESZÁROS, I. Para além do capital: rumo a uma teoria da transição. São Paulo: Boitempo; Campinas: Unicamp, 2002.

NUNES, J.O.R.; PERUSI, M.C.; PETERLINI, G.H.C.; TIEZZI, R.O.; PISANI, R.J. E SANTANA, E.L. Variações texturais dos Latossolos Vermelhos do Assentamento Rural Antônio Conselheiro-Mirante do Paranapanema/SP. Geografia em Atos (UNESP), v. 1, p. 30-39, 2006.

OLIVEIRA, A.U. A Agricultura Camponesa no Brasil. São Paulo: Contexto, 1991.

OLIVEIRA, A . U. de. Etanol, o novo mito do agronegócio. Texto elaborado para o Jornal Sem Terra (08/04/2007).

PALETTA, C. E. M. Setor Sucroalcooleiro. In: GREENPEACE, Dossiê Energia Positiva para 0 Brasil. $2004 . \quad$ Disponível em: http://www.greenpeace.org.br/tour2004_energia/downloads/dossie_energia_2004.pdf. Acesso : set. de 2012.

RODRIGUES, D., ORTIZ, L. S. Em direção à sustentabilidade da produção de etanol de cana de açúcar no Brasil. Outubro, 2006. Disponível em: 
http://www.natbrasil.org.br/Docs/biocombustiveis/sustentabilidade_etanol_port.pdf. Acesso: set. de 2012.

SABOURIN, Eric. Que política pública para a agricultura familiar no segundo governo Lula? In: Sociedade e Estado, volume 22, №. 3, Brasília, setembro/dezembro 2007.

SZMRECSÁNYI, T. Tecnologia e degradação ambiental: o caso da agroindústria canavieira no Estado de São Paulo. In: Informações Econômicas, SP, v.24, n.10, out. 1994.

SILVA, José Graziano. A nova dinâmica da agricultura brasileira, Campinas: Ed. Unicamp, 1996.

SILVA, M A. M. Agronegócio: a reinvenção da colônia. In: SILVA, M. A. M. Agrocombustíveis solução?: a vida por um fio no eito dos canaviais. São Paulo: CCJ - Centro de Capacitação da Juventude, 2008.

WELCH, Clifford Andrew; FERNANDES, Bernardo Mançano. Agricultura e Mercado: campesinato e agronegócio da laranja nos EUA e Brasil. In; Campesinato e territórios em disputa. PAULINO, Eliane Tomiasi; FABRINI, João Edmilson, São Paulo: Expressão Popular, 2008, p. 161-190. 